\title{
Effect of Social Media Spiritual and Emotional Abuse Messages on Comprehension and Behavioural Practices of Married Couples in Lagos State, Nigeria
}

\author{
Helen Odunola Adekoya ${ }^{1}$, Oluwaferanmi Moyosore Adebayo ${ }^{1} \&$ Kolade Ajilore ${ }^{1}$ \\ ${ }^{1}$ Babcock University, Ilishan- Remo, Ogun State, Nigeria \\ Correspondence: Helen Odunola Adekoya, Babcock University, Ilishan- Remo, Ogun State, Nigeria.
}

Received: March 18, 2019 Accepted: April 29, 2019 Online Published: May 14, 2019

doi:10.5539/gjhs.v11n6p146 URL: https://doi.org/10.5539/gjhs.v11n6p146

\begin{abstract}
Evidence from media reports affirmed a progressive increase in incidences of domestic violence globally and in Nigeria. Spiritual and emotional abuse which may have negative consequences on the emotional and psychological wellbeing of the victims are existing forms of domestic violence that are taken with levity based on the entrenched religious and patriarchal systems that are perceived as customary in the Nigerian society. The major objective of this study was to to determine the effect of social media spiritual and emotional abuse messages on comprehension and behavioral practices of married couples in Lagos State, Nigeria. The study employed the true-experimental design for randomization of participants into the experimental and control groups. Study population was non-finite and participants were selected using the proportionate, convenience and purposive sampling techniques. Out of the selected 180 couples, 176 met the inclusion criteria set for the research. Using the Self-structured questionnaire, the results showed a significant difference in married couples' knowledge, comprehension and behavioural practices of spiritual and emotional abuse, before and after the social media intervention. The study concluded that lack of knowledge and comprehension regarding spiritual and emotional abuse is based on dearth of information. This is an indication of intervention effectiveness. Increased inspiring campaigns and programs on social media that will involve married people and the general public in generating contents on spiritual and emotional abuse was recommended. This would induce intentional sourcing for domestic violence information on social media.
\end{abstract}

Keywords: comprehension, behavioural practices, domestic violence, knowledge, social media

\section{Introduction}

One amongst several issues hindering the progressive development of the Nigerian society is domestic violence which often occurs with people who are married or are cohabiting (Ekundayo, Babatunde, \& Ake, 2015). In Nigeria, reports regarding domestic violence are made daily. Such reports range from baby making factories, husbands killing their wives and vice versa. Ishola (2016) added that Nigerian women are physically and sexually assaulted by their relatives, and even killed for trivial offences such as not preparing meals on time and visiting family members without their husband's consent.

The issue of domestic violence is deeply rooted in the Nigerian society such that it poses a threat to job performance and execution. Oni-Ojo, Adeniji, Osibanjo and Heirsmac (2014) assert that, more than 20 percent of employed women in Nigeria take a leave of absence from work and two percent of them lose their jobs due to their experiences with domestic violence. Although women and children experience domestic violence the most, men could also be victims of domestic abuse. Namadi (2017) notes that although domestic violence is common among women, a man is abused by his female partner every 14.6 seconds but reports are not made due to fear of humiliation and being viewed as weak. Nwannekanma and Salau (2017) buttress that in 2016, just 14 men were reported by the Lagos State's Domestic \& Sexual Violence Response Team (DSVRT) to have suffered from domestic violence in Lagos State while in 2017, the number of abused men increased to fifty-five. Furthermore, Awodipe and Azuh (2018) note that 87 domestically abused men had reached out to the Lagos State DSVRT in 2018.

In spite of the amended 1999 Constitution of the Federal Republic of Nigeria under Section 34(1a) that states that "every individual is entitled to respect for the dignity of his person, and accordingly no person shall be subject to 
torture or to inhuman or degrading treatment", people (men and women) are being reported to have suffered varying degrees of abuse, including underage marriage, neglect, gender syndrome abuse and other forms of brutality in different shades and levels. According to the United Nations (2016), 16 percent of married individuals in Nigeria experienced physical or sexual violence in 2016, 11 percent of people in relationships also experienced physical and sexual violence while two percent of single persons experienced the same level of violence which is 29 percent in total. Nwannekanma and Salau (2017) also note that the Lagos State DSVRT recorded 852 cases of domestic violence from January to September, 2017. Olowoopejo (2018) further states that the statistics presented by the DSVRT revealed 3,089 cases of domestic violence in Lagos state from January to August, 2018. This indicates that the domestic violence menace is growing out of control in spite of the legislations and efforts put in place to protect individuals. To this end, the need for better implementation towards securing individuals human rights has become all the more imperative. It is the state, with its various institutions, that is mainly accountable for assuring the execution of these rights for the privilege of citizens and all those under its power (Dada, 2012).

Despite the fact that domestic violence is a rising menace surrounding people's lives in the Nigerian society, it is rarely recognized as a problem because it is regarded as customary in the country (Ishola, 2016). The various forms of domestic violence such as physical, sexual, emotional, economic and psychological abuse, impinges on every individual in the society. Religion has also had its effect on the society given that, religion and customs have made Nigeria a patriarchal society such that women are perceived as the "weaker sex" and biased deeds by men in the society are overlooked (Ekhator, 2015). Buttressing this view, Ngwankwe (2002) asserts that "the traditions and culture of every society determine the values and behavioural patterns of the people and society; a culture that attributes superiority to one sex over the other, exposes the sex that is considered to be inferior to various forms of discrimination"(p.143).

Aihie (2009) avers that spiritual abuse is a form of domestic violence that involves preventing an individual from participating in his/her spiritual or religious activities or using one's religious beliefs to influence or govern $\mathrm{him} /$ her. Individuals who experience these forms of abuse frequently undergo emotional and behavioural problems such as tension, guilt, anxiety, despair and feelings of insecurity (Ekundayo et al., 2015). Reported cases of the spiritual aspect of domestic violence is scarce, yet its existence has many negative consequences. Nigeria is a nation where Islam and Christianity are the two dominant religions that are deeply entrenched in the culture of the people. Arugu (2014) states that religious differences in marriage such as inter-religious and inter-denominational variances are factors that contributes to failed marriages (divorce). The high rate of divorce can be partly attributed to differences in religious beliefs and emotional abuse (Omoniyi-Oyafunke, Falola, \& Salau, 2014).

In Nigeria, the religious beliefs held by the people are deeply internalized such that in marriages, spouses may use their spiritual beliefs to govern or control their partners. This is an act of spiritual abuse which, though not often given prominence, comes with negative emotional effects such as low self-esteem, inferiority complex, guilt, depression and suicidal thoughts. The victims of spiritual abuse are oblivious to the fact that they could be suffering emotional abuse stemming from the myriad effects of spiritual abuse. Fareo (2015) submits that spiritual abuse can be expressed by inhibiting an individual from partaking in his/her spiritual or religious activities, using a person's religious conviction to influence, dictate or control his/her spouse, coercing someone to abide by his/her partner's religious philosophies or making one's spouse convert to another religion entirely. This form of abuse is likely to be accompanied with harsh tones or comments by one's spouse, which does not leave visible scars like injuries, but it is just as agonizing because it leads to emotional trauma like severe low self-esteem, inferiority complex, guilt, depression, anger, resentment, fear and suicidal thoughts (Cochrane, 2016). A major challenge associated with this is that, spiritual abuse is sometimes perceived as customarily right based on the cultural and patriarchal nature and mindset of the Nigerian society, as well as minimal awareness on the issue and its impact on people who barely are aware of it as a form of domestic violence and fail to understand that it also translates into emotional abuse. The effects of emotional abuse are so severe that it threatens a person's behavioural, emotional and mental well-being (Adebayo, 2013).

Due its latent disposition, spiritual abuse is given little or no attention in Nigeria. Religion is profoundly rooted in the culture of the Nigerian people, which is a major reason why spiritual abuse is not readily treated as a form of domestic violence in the country. George and Amusan (2012) corroborating this thought avers that religion is extremely entrenched in the culture of the Nigerian people as it is a powerful force that has a solid influence on social behavior and human relations.

Aihie (2009) avers that, emotional abuse among spouses involves criticism, social isolation, manipulation to control, consistently making unreasonable demands, intimidation and impairment of one's sense of self-worth. Namadi (2017) describes emotional abuse as a pattern of verbal assaults by one's spouse that consist of repeated 
insults, ridicule or name-calling as well as repeated threats to cause emotional pain. This suggests that the saying "sticks and stones may break my bones, but names will never hurt me" can be considered "untrue" in this instance, as the hurt produced in the course of verbal communication is mostly as serious as hurt produced by physical abuse due to the emotional suffering that comes with verbal abuse on individuals (Douglas, 2010).

According to Baran (2012), effective communication is the spread of information from a source to a receiver. Hence, communication to the public concerning spiritual and emotional abuse can be seen as imperative for the conception and maintenance of a positive and suitable milieu in the society. Adaja and Ayodele (2013) assert that a major progress in information and communication technology in the 21 st century was the innovation and rise of social media which eased the establishment of different platforms for social relations. Social networking sites (SNS) such as Instagram, Snapchat, Facebook, YouTube, Twitter, LinkedIn, WhatsApp, Flickr, Tumblr, Pinterest, Google Plus, Skype, Viber, Badoo, Myspace and Vine are employed by people for interacting, establishing relationships, producing and distributing several kinds of electronic messages, and mobilizing citizens to participate in developmental activities in the society.

The importance of social media proficiencies for enlightening, updating, engaging and 'inflaming' the audience such that it holds a transmissible and outreaching influence on people should not be unheeded (Ezeah et al., 2013). $\mathrm{Be}$ that as it may, the existence of communication as the structure of concept circulation has a substantial impact on people involved, as it can incline them to attain a fixed or mutual goal on such issues as spiritual and emotional abuse. Hence, social media can be employed as a tool for creating awareness and spurring married couples to view spiritual and emotional abuse as forms of domestic violence. Premised on these thoughts, the main focus of the study was to determine the effect of social media spiritual and emotional abuse messages on comprehension and behavioural practices of married couples in Lagos State, Nigeria. To effectively achieve this, the study investigated married couples knowledge, comprehension and behavioural practices of spiritual and emotional abuse before and after the social media intervention, guarded by the following hypothesis:

$\mathbf{H}_{\mathbf{1}^{-}}$There is a significant difference in married couple's knowledge of spiritual and emotional abuse before and after the social media intervention.

$\mathbf{H}_{2}$ - There is a significant difference in married couple's comprehension of spiritual and emotional abuse before and after the social media intervention.

$\mathbf{H}_{3^{-}}$There is a significant difference in married couple's behavioural practices of spiritual and emotional abuse before and after the social media intervention.

The scope of this study was Lagos State because as at 2017, it ranked the highest in internet penetration in Nigeria (Adepetun, 2017). Moreover, the specific target audience of this study were married couples because spiritual and emotional abuse are forms of domestic violence that are likely to be carried out in various shades in family settings. As stated by the marriage registries in Lagos state, the accurate statistics of married couples in Lagos state is unknown while others disclosed that the statistics could not be released. Moreover, online statistics of married couples were contradictory. For this reason, the population of this study is non-finite. The intervention for this study was the dissemination of spiritual and emotional abuse messages to respondents through two social media accounts (Facebook and WhatsApp) created for this study by the researchers.

Domestic violence, especially in the forms of spiritual and emotional abuse have become prevalent, thereby constituting obstacles to the progress of the nation in the sense that, it denies members of the society their psychological stability thereby decreasing the competent manpower required to evolve the nation. This study is imperative for public welfare organizations and non-governmental organizations (NGOs) because it would provide better insight on how social media can be used to create awareness, educate the public and uphold acceptable behaviors among the general public. Findings of this study would also help media practitioners to determine where they are defective in order to revise and organize distribution of information for audience members to be more aware of spiritual and emotional abuse. The study is further relevant to the government in the sense that, it would help in guarding, appreciating and valuing citizens by instigating educational programs deep-rooted in curtailing spiritual and emotional abuse. The study is of benefit to married couples in that it would aid them to be more conscious of spiritual and emotional abuse through social media as well as educate them on the threats that these forms of domestic violence may pose to psychological wellbeing of individuals.

Although researches have been conducted on social media and their role/influence in different aspects of domestic violence in many parts of the world, employing experimental research design in discovering social media messages on spiritual and emotional abuse as forms of domestic violence in marriage still remains scarce hence, this study would contribute to the body of knowledge in this field and serve as a foundation for future researches. 


\section{Research Methodology}

The research design implemented in this study is the true-experimental pretest-posttest design. The true-experimental design deals with randomly assigning subjects to different groups. In this design, there are two groups to be investigated and they are the experimental group and the control group; the intervention is revealed to respondents in the experimental group while the intervention is not revealed to respondents in the control group (McMillan \& Schumacher, 2006). The intervention was administered only to the experimental groups in order to examine the effect of the intervention on their knowledge and comprehension of spiritual and emotional abuse as well behavioural practices that reflect spiritual and emotional abuse after the administration of the intervention (post-test). The true-experimental research design is appropriate for this research because the aim is to find out if social media intervention on spiritual and emotional abuse will have an effect on married couples knowledge, comprehension and behavioural practices of spiritual and emotional abuse.

In this study, there were two experimental groups and two controls groups. Experimental group A had spiritual and emotional abuse messages conveyed through Facebook while control group A was not exposed to spiritual and emotional abuse messages. Experimental group B had spiritual and emotional abuse messages conveyed through WhatsApp while control group B was not exposed to spiritual and emotional abuse messages. Married couples who reside in Lagos State were randomly assigned to the four groups. The sample size was drawn using the formula for non-finite population. According to Godden (2004), the sample size of a non-finite population can be determined where the population is greater than 50,000 .

$$
\mathrm{n}=\frac{Z^{2} \times p(1-p)}{M^{2}}
$$

Where:

\begin{tabular}{|c|c|}
\hline \multicolumn{2}{|c|}{$\mathrm{n}=$ sample size for non-finite population } \\
\hline \multicolumn{2}{|c|}{$Z=Z$ value (e.g. 1.96 for $95 \%$ confidence level) } \\
\hline \multicolumn{2}{|c|}{$\mathrm{P}=$ population proportion (assumed to be $0.10(10 \%)$} \\
\hline \multicolumn{2}{|c|}{$\mathrm{M}=$ margin of error at $5 \%(0.05)$} \\
\hline $\mathrm{n}=$ & $1.96^{2} \times 0.10(1-0.10)$ \\
\hline \multirow{3}{*}{$=$} & $(0.05)^{2}$ \\
\hline & $\underline{3.8416 \times 0.10(0.9)}$ \\
\hline & 0.0025 \\
\hline \multirow[t]{2}{*}{$=$} & $\underline{3.8416 \times 0.09}$ \\
\hline & 0.0025 \\
\hline \multirow[t]{2}{*}{$=$} & $\underline{0.345744}$ \\
\hline & 0.0025 \\
\hline$=$ & 138 \\
\hline
\end{tabular}

In addition, thirty percent (30\%) of the sample size was calculated to take care of attrition effect. This will strengthen the study in having adequate respondents to complete the goal of this research. Therefore;

$$
\begin{aligned}
& \frac{30 \times 138}{100}=41.5 \\
& 138+41.5=179.5 \_180 \\
& \text { Sample size }=180
\end{aligned}
$$

The proportionate, convenience and purposive sampling methods were used in this study. Firstly, 180 copies of questionnaire were equally distributed in the 20 Local Government Areas (LGA) in Lagos State. That is, 9 copies of the questionnaire were administered in each LGA and they were distributed based on availability of married couples in the LGA's. The local government areas are; Agege, Ajeromi-Ifelodun, Alimosho, Amuwo-Odofin, Apapa, Badagry, Epe, Eti-Osa, Ibeju-Lekki, Ifako Ijaiye, Ikeja, Ikorodu, Kosofe, Lagos Island, Lagos Mainland, Mushin, Ojo, Oshodi-Isolo, Shomolu and Surulere.

Using the purposive sampling method, respondents from the LGA's were selected by inclusion and exclusion criteria set by the researchers. Inclusion and exclusion criteria were set to determine married couples who are 
eligible and not eligible for the study. The inclusion criteria was: (a) people that are married or have been married at one point or the other (b) having a Facebook or WhatsApp account (c) visitation of the Facebook or WhatsApp account at least 2 times in a week. The exclusion criteria was: (a) being a married person residing in another state (b) No active Facebook or WhatsApp account. Married couples who met these criteria were asked for their WhatsApp numbers and with this, the researchers added them to group created for the study. For the Facebook group, the researchers also requested for research participants Facebook account names and with this, the researchers sent a friend request to them on Facebook in order to ensure their participation in the study.

The intervention for this study were spiritual and emotional abuse messages to respondents through Facebook and WhatsApp accounts created for this study by the researchers. The first stage involved the gathering of spiritual and emotional abuse materials (texts, audio, images and videos on spiritual and emotional abuse). Stage two entailed a pre-test data gathering, where copies of a self-constructed structured questionnaire were administered to both the experimental and control groups of the study to get respondents basic knowledge and comprehension of spiritual and emotional abuse as well as their behavioural practices that reflect spiritual and emotional abuse. This was conducted to present indices for comparison at the end of the intervention. Stage three was the beginning and execution of the social media messages on spiritual and emotional abuse which lasted for 4 weeks, from $2^{\text {nd }}$ November, 2018 to $30^{\text {th }}$ November, 2018. Messages on spiritual and emotional abuse were posted daily on the Facebook and WhatsApp accounts created for participants in the experimental groups while respondents in the control groups were not exposed to the spiritual and emotional messages.

After the 4 week period of dissemination of social media messages on spiritual and emotional abuse, a post-test data was collected from both the experiment groups and the control group using the same set of questions administered at the pre-test. The aim was to determine whether the social media intervention had an impact on the respondents' knowledge and comprehension of spiritual and emotional abuse as well as their behavioural practices. Questionnaire developed by the researchers was used at both the pre-test and post-test to collect data from experimental groups and control groups.

180 copies of questionnaire were distributed by the researchers and two trained research assistants from the University of Lagos. A proportionate distribution of 9 copies of questionnaire was done based on the availability of married couples across the 20 local government areas in Lagos state, Nigeria (convenience). The first phase of gathering data was done before the intervention (pre-test) while the second phase was at the end of the social media intervention (post-test). Because the experiment was carried out using two social media platforms (Facebook \& WhatsApp), there were two experimental groups and two control groups in this study. That is, the 180 married couples were randomly assigned into experimental groups and control groups as follow: 45 participants in experimental group A (Facebook) and 45 participants for the control group A. The experimental group B (WhatsApp) had 45 participants and 45 participants in the control group B.

At the pre-test stage, the questionnaire was administered to all participants. In Section A, number 6 of the questionnaire, it was required of the participants to put down their Facebook account names and WhatsApp number. Based on the research employing the true experimental design that deals with randomly assigning subjects to different groups, the researchers randomly assigned participants to the social media experimental groups and control groups based on the information given regarding their social media accounts. This enabled the researchers have a direct communication with the participants as well as add them to the formed Facebook and WhatsApp groups. Subsequently, the intervention was administered for 4 weeks to the participants in the Facebook and WhatsApp experimental groups while the control groups were not exposed to the intervention.

At the post-test stage, the same questionnaire was administered to the same participants who at this phase had already been randomly assigned to the different groups. This enabled the researchers to examine the effect of the intervention on the participants.

To test the hypotheses, paired T-test was the inferential analysis statistics used for determining the significant difference in the experimental and control groups' knowledge, comprehension and behavioural practices of domestic violence before and after the intervention.

\section{Data Analysis, Results and Discussion of Findings}

\subsection{Test of Hypotheses}

\subsubsection{Decision Rule}

The Paired samples T-test is adopted for the test of hypotheses. If the p-value, which is the probability value, was less or equal to 0.05 , the hypothesis was accepted, while if $\mathrm{p}$ value was greater than 0.05 , the hypothesis was rejected. 
$\mathbf{H}_{\mathbf{1}}$ - There is a significant difference in married couples' knowledge of domestic violence before and after the social media intervention.

Table 1a. Paired Samples T-Test Statistics of Knowledge of Domestic Violence Before and After for Experimental Group

\begin{tabular}{lllll}
\hline Variable & Mean & N & Std. Deviation & Std. Error Mean \\
\hline Knowledge Experiment Pre & 47.6235 & 88 & 11.52896 & 1.22899 \\
Knowledge Experiment Post & 59.6212 & 88 & 9.19908 & .98062 \\
\hline
\end{tabular}

Table 1b. Paired Samples T-Test Analysis of Knowledge of Domestic Violence Before and After for Experimental Group

\begin{tabular}{|c|c|c|c|c|c|c|c|c|}
\hline & \multicolumn{5}{|c|}{ Paired Differences } & \multirow{3}{*}{$\mathbf{T}$} & \multirow{3}{*}{ Df } & \multirow{3}{*}{$\begin{array}{l}\text { Sig. } \\
\text { (2-tailed) }\end{array}$} \\
\hline & \multirow[t]{2}{*}{ Mean } & \multirow{2}{*}{$\begin{array}{l}\text { Std. } \\
\text { Deviation }\end{array}$} & \multirow{2}{*}{$\begin{array}{l}\text { Std. Error } \\
\text { Mean }\end{array}$} & \multicolumn{2}{|c|}{$\begin{array}{l}95 \% \text { Confidence Interval of the } \\
\text { Difference }\end{array}$} & & & \\
\hline & & & & Lower & Upper & & & \\
\hline $\begin{array}{l}\text { Knowledge } \\
\text { Experiment Pre }\end{array}$ & -11.99773 & 14.88367 & 1.58660 & -15.15128 & -8.84418 & -7.562 & 87 & 0.000 \\
\hline $\begin{array}{l}\text { Knowledge } \\
\text { Experiment Post }\end{array}$ & & & & & & & & \\
\hline
\end{tabular}

From Table $1 \mathrm{~b}$, there was a significant difference in participants' knowledge of domestic violence before and after the social media intervention for the experimental group (Mean Difference $=11.99773, \mathrm{p}<0.05$ ). This implies that the social media intervention played a significant role in increasing knowledge of domestic violence for the experimental group. Consequently, the hypothesis was accepted.

Table 2a. Paired Samples T-Test Statistics of Knowledge of Domestic Violence Before and After for Control Group

\begin{tabular}{lllll}
\hline Variable & Mean & N & Std. Deviation & Std. Error Mean \\
\hline Knowledge Control Pre & 49.5917 & 88 & 11.09437 & 1.18266 \\
Knowledge Control Post & 49.3159 & 88 & 11.50901 & 1.22686 \\
\hline
\end{tabular}

Table 2b. Paired Samples T-Test Analysis of Knowledge of Domestic Violence Before and After for Control Group

\begin{tabular}{|c|c|c|c|c|c|c|c|c|}
\hline & \multicolumn{5}{|c|}{ Paired Differences } & \multirow{3}{*}{$\mathbf{T}$} & \multirow{3}{*}{ Df } & \multirow{3}{*}{$\begin{array}{l}\text { Sig. } \\
\text { (2-tailed) }\end{array}$} \\
\hline & \multirow[t]{2}{*}{ Mean } & \multirow{2}{*}{$\begin{array}{l}\text { Std. } \\
\text { Deviation }\end{array}$} & \multirow{2}{*}{$\begin{array}{l}\text { Std. Error } \\
\text { Mean }\end{array}$} & \multicolumn{2}{|c|}{$\begin{array}{l}95 \% \text { Confidence Interval of the } \\
\text { Difference }\end{array}$} & & & \\
\hline & & & & Lower & Upper & & & \\
\hline $\begin{array}{l}\text { Knowledge } \\
\text { Control Pre }\end{array}$ & 0.27576 & 1.58199 & 0.16864 & -0.05943 & 0.61095 & 1.635 & 87 & 0.106 \\
\hline \multicolumn{9}{|l|}{ Knowledge } \\
\hline Control Post & & & & & & & & \\
\hline
\end{tabular}

Table $2 b$ indicates that there was no significant difference in participants' knowledge of domestic violence before and after the social media intervention for the control group ( $p>0.05$ ). This suggests that participants' knowledge level was relatively significantly similar, hence, it could be assumed that this was as a result of not taking part in the social media intervention.

$\mathbf{H}_{2}$ - There is a significant difference in married couple's comprehension of domestic violence before and after the 
social media intervention.

Table 3a. Paired Samples T-Test Statistics of Comprehension of Domestic Violence Before and After for Experimental Group

\begin{tabular}{lllll}
\hline Variable & Mean & N & Std. Deviation & Std. Error Mean \\
\hline Comprehension Experiment Pre & 26.4477 & 88 & 9.54650 & 1.01766 \\
Comprehension Experiment Post & 57.6167 & 88 & 10.26468 & 1.09422 \\
\hline
\end{tabular}

Table 3b. Paired Samples T-Test Analysis of Comprehension of Domestic Violence Before and After for Experimental Group

\begin{tabular}{|c|c|c|c|c|c|c|c|c|}
\hline & \multicolumn{5}{|c|}{ Paired Differences } & \multirow{3}{*}{$\mathbf{T}$} & \multirow{3}{*}{ Df } & \multirow{3}{*}{$\begin{array}{l}\text { Sig. } \\
\text { (2-tailed) }\end{array}$} \\
\hline & \multirow[t]{2}{*}{ Mean } & \multirow{2}{*}{$\begin{array}{l}\text { Std. } \\
\text { Deviation }\end{array}$} & \multirow{2}{*}{$\begin{array}{l}\text { Std. Error } \\
\text { Mean }\end{array}$} & \multicolumn{2}{|c|}{$\begin{array}{l}95 \% \text { Confidence Interval of } \\
\text { the Difference }\end{array}$} & & & \\
\hline & & & & Lower & Upper & & & \\
\hline $\begin{array}{l}\text { Comprehension } \\
\text { Experiment Pre }\end{array}$ & -31.16894 & 12.58983 & 1.34208 & -28.50141 & -33.83647 & -23.224 & 87 & 0.000 \\
\hline $\begin{array}{l}\text { Comprehension } \\
\text { Experiment Post }\end{array}$ & & & & & & & & \\
\hline
\end{tabular}

From Table 3b, there was a significant difference in participants' comprehension of domestic violence before and after the social media intervention for the experimental group (Mean Difference $=31.16894, \mathrm{p}<0.05$ ). This implies that the social media intervention played an important role in increasing participants' comprehension of domestic violence for the experimental group. Therefore, the hypothesis was accepted.

Table 4a. Paired Samples T-Test Statistics of Comprehension of Domestic Violence Before and After for Control Group

\begin{tabular}{lllll}
\hline Variable & Mean & N & Std. Deviation & Std. Error Mean \\
\hline Comprehension Control Pre & 55.8697 & 88 & 10.15445 & 1.08247 \\
Comprehension Control Post & 55.4697 & 88 & 10.18545 & 1.08577 \\
\hline
\end{tabular}

Table 4b. Paired Samples T-Test Analysis of Comprehension of Domestic Violence Before and After for Control Group

\begin{tabular}{|c|c|c|c|c|c|c|c|c|}
\hline & \multicolumn{5}{|c|}{ Paired Differences } & \multirow{3}{*}{$\mathbf{T}$} & \multirow{3}{*}{ Df } & \multirow{3}{*}{ Sig. (2-tailed) } \\
\hline & \multirow{2}{*}{ Mean } & \multirow{2}{*}{$\begin{array}{l}\text { Std. } \\
\text { Deviation }\end{array}$} & \multirow{2}{*}{$\begin{array}{l}\text { Std. Error } \\
\text { Mean }\end{array}$} & \multicolumn{2}{|c|}{$\begin{array}{l}95 \% \text { Confidence Interval } \\
\text { of the Difference }\end{array}$} & & & \\
\hline & & & & Lower & Upper & & & \\
\hline $\begin{array}{l}\text { Comprehension } \\
\text { Control Pre }\end{array}$ & 0.40000 & 1.14207 & .12174 & .15802 & .64198 & 3.286 & 87 & 0.001 \\
\hline $\begin{array}{l}\text { Comprehension } \\
\text { Control Post }\end{array}$ & & & & & & & & \\
\hline
\end{tabular}

From Table $4 b$, there was a significant difference in participants' comprehension of domestic violence before and after the intervention for the control group (Mean Difference $=0.4, \mathrm{p}<0.05$ ). This suggests that participants' comprehension of domestic violence was not significantly the same before and after the intervention for the control group. This might have resulted because participants interacted with sources that influenced their comprehension of domestic violence other than the social media intervention which was not administered to them. 
$\mathbf{H}_{3}$ - There is a significant difference in married couple's behavioural practices of domestic violence before and after the social media intervention.

Table 5a. Paired Samples T-Test Statistics of Behavioural Practices of Domestic Violence Before and After for Experimental Group

\begin{tabular}{lllll}
\hline Variable & Mean & N & Std. Deviation & Std. Error Mean \\
\hline Behavioural Experiment Pre & 33.7621 & 88 & 10.95274 & 1.16757 \\
Behavioural Experiment Post & 24.0545 & 88 & 3.21019 & 0.34221 \\
\hline
\end{tabular}

Table 5b. Paired Samples T-Test Analysis of Behavioural Practices of Domestic Violence Before and After for Experimental Group

\begin{tabular}{|c|c|c|c|c|c|c|c|c|}
\hline & \multicolumn{5}{|c|}{ Paired Differences } & \multirow{3}{*}{$\mathbf{T}$} & \multirow{3}{*}{ Df } & \multirow{3}{*}{ Sig. (2-tailed) } \\
\hline & \multirow[t]{2}{*}{ Mean } & \multirow{2}{*}{$\begin{array}{l}\text { Std. } \\
\text { Deviation }\end{array}$} & \multirow{2}{*}{$\begin{array}{l}\text { Std. Error } \\
\text { Mean }\end{array}$} & \multicolumn{2}{|c|}{$\begin{array}{l}95 \% \text { Confidence Interval } \\
\text { of the Difference }\end{array}$} & & & \\
\hline & & & & Lower & Upper & & & \\
\hline $\begin{array}{l}\text { Behavioural } \\
\text { Experiment Pre }\end{array}$ & 9.70758 & 10.73005 & 1.14383 & 7.43410 & 11.98106 & 8.487 & 87 & 0.000 \\
\hline $\begin{array}{l}\text { Behavioural } \\
\text { Experiment Post }\end{array}$ & & & & & & & & \\
\hline
\end{tabular}

Table $5 \mathrm{~b}$ indicates that there was a significant difference in participants' behavioural practices of domestic violence before and after the social media intervention for the experimental group (Mean Difference $=9.70758, \mathrm{p}<0.05$ ). This suggests that the social media intervention played an important role in changing participants' behavioural practices of domestic violence for the experimental group. Hence, the hypothesis was accepted.

Table 6a. Paired Samples T-Test Statistics of Behavioural Practices of Domestic Violence Before and After for Control Group

\begin{tabular}{lllll}
\hline Variable & Mean & N & Std. Deviation & Std. Error Mean \\
\hline Behavioural Control Pre & 33.2795 & 88 & 9.61558 & 1.02502 \\
Behavioural Control Post & 33.4803 & 88 & 9.52109 & 1.01495 \\
\hline
\end{tabular}

Table 6b. Paired Samples T-Test Analysis of Behavioural Practices of Domestic Violence Before and After for Control Group

\begin{tabular}{|c|c|c|c|c|c|c|c|c|c|}
\hline & \multicolumn{6}{|c|}{ Paired Differences } & \multirow{3}{*}{$T$} & \multirow{3}{*}{ Df } & \multirow{3}{*}{ Sig. (2-tailed) } \\
\hline & \multirow{2}{*}{ Mean } & \multirow{2}{*}{$\begin{array}{l}\text { Std. } \\
\text { Deviation }\end{array}$} & \multirow{2}{*}{$\begin{array}{l}\text { Std. } \\
\text { Mean }\end{array}$} & \multirow[t]{2}{*}{ Error } & \multicolumn{2}{|c|}{$\begin{array}{l}95 \% \text { Confidence Interval of } \\
\text { the Difference }\end{array}$} & & & \\
\hline & & & & & Lower & Upper & & & \\
\hline $\begin{array}{l}\text { Behavioural } \\
\text { Control Pre }\end{array}$ & -.20076 & 1.08474 & .11563 & & -.43059 & .02908 & -1.736 & 87 & 0.086 \\
\hline $\begin{array}{l}\text { Behavioural } \\
\text { Control Post }\end{array}$ & & & & & & & & & \\
\hline
\end{tabular}

Table $6 \mathrm{~b}$ shows that there was no significant difference in participants' behavioural practices of domestic violence before and after the social media intervention for the control group ( $p>0.05)$. This implies that participants' behavioural practices were significantly similar, hence, it could be assumed that this was as a result of not taking part in the social media intervention. 


\section{Discussion of Findings}

The first hypothesis tested in relation to this revealed that there is a significant difference in participants' knowledge of domestic violence before and after the social media intervention for the experimental group (Pre-intervention mean $=47.6235$; Post-intervention mean $=59.6212, \mathrm{p}<0.05)$ see Table 1a. However, because the intervention was not exposed to the control group, the result of the hypothesis revealed that there was no significant difference in participants' knowledge of domestic violence before and after the social media intervention. In fact, there was a slight reduction in their knowledge of domestic violence at the post-intervention (Pre-intervention mean $=49.5917$; Post-intervention mean $=49.3159)$. This points out that the social media intervention which was not administered to them, was not the factor responsible for this decrease. With this, it is safe to aver that the social media intervention resulted in married couples' high knowledge of domestic violence (spiritual and emotional abuse); indicating that the social media intervention carried out was effective. This is as there was an observed increase in married couples' knowledge about preventing one's spouse from practicing his/her religious doctrines, coercing one's spouse to follow his/her partners religious beliefs/affiliations, imposing change of denomination/religion on one's spouse, using spouses' beliefs to manipulate his/her actions, employing religious teachings as a defence for control or violence as well as insulting, ridiculing and threatening one's spouse because of his/her religious beliefs/affiliations.

In this study, married couples are not knowledgeable on the issue of spiritual and emotional abuse as forms of domestic violence at the pre-intervention stage. Married couple's dearth of knowledge on spiritual and emotional abuse before the intervention validates the assertion that, based on the religious stance of the society, spiritual abuse is hardly known as a form of domestic violence which may account for the seemingly low number of reported cases by the victims and even the media. The finding of this study together with that of Corbett (2013) confirms that lack of knowledge on emotional abuse can be as a result of the perception that emotional is a bruise to the mind and not the body so it is undetectable. Hence, the saying "sticks and stones may break my bones, but names will never hurt me" can be considered "untrue" given that, words or actions that produce internal hurt (emotional abuse) is considered even more serious that physical abuse (Douglas, 2010). At the post-intervention stage however, married couples became highly knowledgeable so it is safe to say that the social media intervention on domestic violence was effective. According to Sutherland, Simons and Blatchford (2017), social media has changed the manner in which people seek and exchange information. Moreover, social media is a part of the range of interventions that are needed to prevent issues such as Violence against Women (VAW) (Liou, 2013). Therefore, social media has the power to influence and mobilize people to strive towards obliterating domestic violence especially, spiritual and emotional abuse in marriage.

According to Troedson (2009), "knowledge is made out of information" (p.2). Therefore, having information is vital to knowledge in the sense that, participants in this study were not knowledgeable about spiritual and emotional abuse as forms of domestic violence because they did not have the necessary information. However, after they had access to information on spiritual and emotional abuse on social media, their knowledge improved to a great extent. The essence of knowledge should not be overlooked because if knowledge is present, individuals can make the right decisions such as knowing when abused, speaking up when abused and sharing experiences of the abuse to help victims.

Furthermore in Table 3a\&b, Hypothesis 2 showed that there was a significant difference in participants' comprehension of domestic violence before and after the social media intervention for the experimental groups (Pre-intervention mean $=26.4477$; Post-intervention mean $=57.6167, \mathrm{p}<0.05)$. For the control group however, it was revealed that there was a significant difference in participants' comprehension of domestic violence before and after for the intervention (Mean Difference $=0.4, \mathrm{p}<0.05$ ). This implies that before and after the intervention, participants' comprehension of domestic violence was not significantly the same which may be as a result of coming across sources that altered their comprehension of domestic violence other than the social media intervention that was not administered to them. It is therefore, inferred that the social media intervention for the experimental group resulted in married couples high comprehension of domestic violence; meaning that the social media intervention administered was effective.

Taking into account that before the administration of the intervention, participants were not knowledgeable of spiritual and emotional abuse being forms of domestic violence, findings further showed that they also had no understanding of spiritual and emotional abuse being forms of domestic violence. This may be as a result of individuals not observing such actions as detrimental because of the mind-set and practices of the society that permits spiritual and emotional abuse to be a norm. Troedson (2009) elucidates that acquisition of knowledge is born out of information while understanding is based on experience and not knowledge. This suggests that married 
couples in this study had no knowledge of spiritual and emotional abuse being forms of domestic violence because they had no information. Furthermore, the participants did not understand this subject matter as a problem because of the experiences encountered in the Nigerian society. In the Nigerian society, the act and practice of spiritual and emotional abuse as a norm is based on the profound religious and patriarchy system put in place (Ekhator, 2015; Ishola, 2016).

These inferences agree with the tenets of the critical tradition theory. The theory explains that critical tradition strives for understanding on the taken-for-granted systems, power structure and beliefs or ideologies that govern a society in order to determine whose interests are served by those power structures. This is the case with domestic violence especially spiritual and emotional abuse in the sense that, they are treated with levity because the Nigerian society is deeply internalized in religion and patriarchy, where men are regarded as superior and must be in charge. In the studies of Bazza, (2009); Ekhator, (2015); Manful, Appiah and Gyasi-Boadu (2016) and Mbadugha (2016) it was highlighted that religion and patriarchy are major reasons domestic violence began and is still existing in Africa and Nigeria. This system has become unsafe to both men and women because men are also abused but the fear of being viewed as weak and criticized for sharing their experience as victims of domestic violence would not allow them voice out in view of the fact that they are culturally considered as superior to women so they must act accordingly. Women on the other hand also do not gain from this system because they are expected to be silent when abused based on the patriarchal culture of the Nigerian society.

With this, the essence of people really knowing and understanding what is right and wrong in order to avoid spiritual and emotional abuse should not be understated. In view of the critical theory, Seiler (2018) asserted that information permits an individual to comprehend the ways (s) he could be oppressed, thereby enabling him/her to take necessary actions when confronted by repressive forces. Elgin (2006) also attested that a slight understanding of a phenomenon permits individuals to identify uncivilized structures, make rough explanations and have a broad spectrum of thoughts. This also suggests that the improvement of understanding makes an individual's intellectual capacity, descriptions and deductions to become more developed. This could be the possible reason why participants understood spiritual and emotional abuse as forms of domestic violence after the intervention was given in the sense that, the treatment gave them deeper insight and broadened their knowledge on spiritual and emotional abuse which caused them to eventually comprehend them as forms of domestic.

The test of the last hypothesis portrayed in Table 5a that there is a significant difference in participants' behavioural practices of domestic violence before and after the social media intervention for the experimental group (Pre-intervention mean $=33.7621$; Post-intervention mean $=24.0545, \mathrm{p}<0.05)$. This finding correlates to the point made by Adaja and Ayodele (2013) that a major progress in information and communication in the modern-day is the innovation and rise of social media which eases the establishment of different platforms for public interaction. Trevithick (2000) stated that information gained and experiences shared from good communication will open new avenues and modify forthcoming actions. Sutherland, McCormack, Pirkis, Easteal, Holland and Vaughan (2015) further added that the way information is passed across to the public will have a profound effect on their attitudes, beliefs and behaviours towards the subject matter. It is therefore safe to note that in this study, participants behavioural practices of domestic violence at the post-intervention was influenced by the social media domestic violence message intervention. The information obtained by the participants though the treatment caused them to act differently.

Furthermore, the findings here authenticates the assumption of the social learning theory that states that individuals behave according to their observation of other people's behaviour which eventually serves as a guide for future actions. Before the intervention in this study, participants noted that they modelled the behaviour of their parents. This indicates that married couples who perpetrated spiritual and emotional abuse may have learned this form of abuse from their parents which they used as a springboard for themselves in their own marriages. This gives credence to the conclusion drawn by Anaeto, Onabajo and Osifeso (2008) that a considerable amount of action occurs through studying the behaviour of others. Moreover, married couples in this study also expressed that they acted based on their Biblical/Islamic injunctions which indicates that they conducted themselves by modelling their religious and denominational doctrines. George and Amusan (2012) affirmed that religion is extremely entrenched in the Nigerian culture as it is a powerful force that has a solid influence on social behaviour of the people.

As a result of the findings of this study, the researchers recommended that since married couples' employment of social media as sources of domestic violence information is passive, public welfare organizations and non-governmental organizations (NGOs) organizations should establish inspiring campaigns on social media that will involve married people generating contents on spiritual and emotional abuse. This will push them to willfully 
seek out spiritual and emotional abuse information on social media. It is essential and necessary to implement gender equality and all policies put in place against the violation of human rights for the purpose of eradicating spiritual and emotional abuse. The government should also ensure that every government owned broadcast station should have a programme or public service announcements on spiritual and emotional abuse as well as reveal the penalty of culprits who use religion and patriarchy as justification for abusing their spouses or anyone. This will help to create more awareness and keep the individuals conscious to avoid breaking the law.

Also, media practitioners should pay significant attention to spiritual and emotional abuse by consistently creating programs where they are extensively discussed. This will help members of the public, especially married couples to be more aware of spiritual and emotional as forms of domestic violence that exist in the Nigerian society and the damaging effects it could have on the psychological well-being of individuals.

\section{Competing Interests Statement}

The authors declare that there are no competing or potential conflicts of interest.

\section{References}

Adaja, T. A., \& Ayodele, F. A. (2013). Nigerian youths and social media: Harnessing the academic excellence. Arabian Journal of Business and Management Review, 2(5), 65-75. https://doi.org/10.12816/0001189

Adebayo, A. A. (2013). Sociological implications of domestic violence on children's' development in Nigeria. Journal of African Studies and Development, 6(1), 8-13. https://doi.org/10.5897/JASD2013.0237

Aihie, O. N. (2009). Prevalence of domestic violence in Nigeria: Implications for counselling. Edo Journal of Counselling, 2(1). https://doi.org/10.4314/ejc.v2i1.52648

Anaeto, S. G., Onabajo, O. S., \& Osifeso, J. B. (2008). Models and Theories of Mass Communication. Maryland: African Renaissance Books Incorporated.

Arugu, L. O. (2014). Social indicators and effects of marriage divorce in African societies. The Business \& Management Review, 4(4).

Awodipe, T., \& Azuh, B. (2018). Only 87 men have spoken up on abuse cases this year, says DSVRT. The Guardian Online, Retrieved from https://www.google.com/amp/s/guardian.ng/guardian-woman/only-87-men-have-spoken-up-on-abuse-cases -this-year-says-dsvrt/amp

Baran, S. J. (2012). Introduction to Mass Communication. Media Literacy and Culture (7th ed.). Byrant University: McGraw-Hill.

Baran, S. J., \& Davis, D. K. (2012). Mass Communication Theory. Foundations, Ferment and Future (6th ed.). USA: Wadsworth, Cengage Learning. https://doi.org/10.1111/j.1468-2885.2012.01402.x

Bazza, H. I. (2009). Domestic violence and women's rights in Nigeria. Societies without borders, 4(2). https://doi.org/10.1163/187219109X447467

Cochrane, J. (2016). Spiritual abuse. Retrieved from https://www.sgm.org.nz/uploads/2/0/1/6/ 20165561/spiritual_abuse.pdf

Corbett, C. (2013). Charming or harming: Case studies of emotional abuse in heterosexual intimate partner relationships. $\quad$ Retrieved from https://researchcommons.waikato.ac.nz/ bitstream/handle/10289/8444/thesis.pdf? sequence $=3$

Douglas, R. (2010). Stick and stones - hurtful words damage the brain. Verbal abuse in childhood inflicts lasting physical offects on brain structure. Retrieved from https://www.psychologytoday.com/blog/the-new-brain/201010/sticks-and-stones-hurtful-words-damage-the -brain

Ebele, N. (2017). Is domestic violence a norm in Nigeria? Retrieved from https:/guardian.ng/ issue/is-domestic-violence-a-norm-in-nigeria/

Ekhator, E. O. (2015). Women and the law in Nigeria: A reappraisal. Journal of International Women's Studies, $6(2), 285-296$.

Ekundayo, B. B., Babatunde, E. D., \& Ake, B. M. (2015). Effects of domestic violence on young people in family setting: Evidence from Omu-Aran, Kwara State, Nigeria. Scientific Research Journal (SCIRJ), 3(I).

Elgin, C. Z. (2006). From knowledge to understanding. Retrieved from elgin.harvard.edu/undg/ undg/kntoun.pdf 
Fareo, D. O. (2015). Domestic violence against women in Nigeria. European Journal of Psychological Research, 2(1).

George, T. O., \& Amusan, T. A. (2012). Religion and acts of worship amongst the Nigerian people: Implications for development and national unity. Retrieved from https://eprints covenantuniversity.edu.ng/832/

Liou, C. (2013). Using social media for the prevention of violence against women. Retrieved from http://www.partners4prevention.org/sites/default/files/resources/socialmedia_final.pdf

Manful, E., Appiah, P. B., \& Gyasi-Boadu, N. (2016). Domestic violence in Africa: Exploring the perceptions of Ghanaian adolescents. Journal of Social Sciences and Humanities, 2(4), 63-70.

Mbadugha, E. I. (2016). Intimate partner violence and sexual violence against women: Any end in sight? International Journal of Medicine and Biomedical Research, 5(1). https://doi.org/10.14194/ijmbr.5.1.2

McMillan, J. H., \& Schumacher, S. (2006). Research in Education. Evidence-Based Enquiry (6thed.). USA: Pearson Education, Inc.

Namadi, M. M. (2017). Nature and prevalence of domestic violence against men in Dala Local government area of Kano state, Nigeria. Journal of Social and Management Sciences, 12(1). DOI: 10.5987/UJ-JSMS.17.055.1

Nwannekanma, B., \& Salau, G. (2017, September 6). Lagos record 852 domestic violence cases in nine months. The Guardian, Retrieved from https:/guardian.ng/news/lagos-records852-domestic-violence-cases-in-nine-months/

Olowoopejo, M. (2018, September 4). Lagos records 3,089 rape, domestic violent cases in 8 months. Vanguard News, Retrieved from ttps:/www.vanguardngr.com/2018/09/lagosrecords-3089-rape-domestic-violent-cases-in-8-months/

Omoniyi-Oyafunke C., Falola, H. O., \& Salau, O. P. (2014). Effect of marital instability on children in Abeokuta metropolis. European Journal of Business and Innovation Research, 2(3), 68-77.

Oni-Ojo, E. E., Adeniji, A. A., Osibanjo, A. O., \& Heirsmac, T. P. (2014). Impact of domestic violence on female employee's productivity in the Nigerian workforce. Retrieved from http://eprints.covenantuniversity.edu.ng/8420/1/4303-12503-1-PB.pdf

Seiler, R. M. (2018). Human communication in the critical theory tradition. Retrieved from: https://www.researchgate.net/publication/265480334_Human_Communication_in_the_Critical_Theory_Tra dition

Statista, (2018). Social media and user-generated content. Penetration of leading social networks in Nigeria as of 3rd quarter 2017. Retrieved from: http://www.statista.com/ statistics/804995/nigeria-social-network-penetration/

Sutherland, G., McCormack, A., Pirkis, J., Easteal, P., Holland, K., \& Vaughan, C. (2015). Media Representations of Violence against Women and their Children: State of Knowledge Paper. Retrieved from: https://www.ourwatch.org.au/getmedia/339a9055-16fb-4d57-8cb3-3d2a2f9c5fa1/Media-representations-ofviolence-against-women-state-knowledge-paper.pdf.aspx

Sutherland, G., Simons, M., \& Blatchford, A. (2017). Emerging, evidence, insights and lessons: News media and the primary prevention of violence against women and their children. Retrieved from https://www.ourwatch.org.au/getmedia/.../Emerging-evidence-guide- media.pdf.aspx

Troedson, T. (2009). On the difference between knowledge and understanding. Retrieved from www.milinstitute.se/pub/arkiv/T_Troedson_paper.pdf

University of Michigan Health System. (2007). Emotional abuse hurts. Physical harm is not the only form of abuse. Retrieved from https://www.med.umich.edu/abusehurts/abuse_emotional.pdf

\section{Copyrights}

Copyright for this article is retained by the author(s), with first publication rights granted to the journal.

This is an open-access article distributed under the terms and conditions of the Creative Commons Attribution license (http://creativecommons.org/licenses/by/4.0/). 